\title{
Criação de municípios e conflitos institucionais no Brasil
}

\section{Creación de municipios y conflictos institucionales en Brasil}

\section{Creation of municipalities and institutional conflicts in Brazil}

\author{
Fernando Mendes de Souza \\ fernandomsza@ufpr.br \\ Universidade Federal do Paraná, UFPR, Curitiba, PR \\ Adilar Antonio Cigolini \\ adilar@ufpr.br \\ Universidade Federal do Paraná, UFPR, Curitiba, PR
}

\begin{abstract}
Resumo: A promulgação da Constituição Federal do Brasil em 1988 atribuiu aos Estados Federados definir os critérios para criação de novos municípios. Esses criaram normas que facilitaram a criação dessas unidades políticas, o que contribuiu para a intensificação de desmembramentos em todo o país. Em razão disso foi aprovada a Emenda Constitucional 15/1996 que impedia que municípios fossem criados até nova regulamentação Federal e aqueles criados sem a existência de uma Lei Federal foram contestados judicialmente. Este trabalho procura desvendar como municípios puderam ser criados e instalados desde então, sem apoio legal, e por quais motivos o Poder Judiciário manteve sua existência. A instalação polêmica desses municípios revela embates políticos, de relações de poder e de concepção de Estado que levam a reflexão sobre o sentido da divisão territorial no Brasil.
\end{abstract}

Palavras-chave: emancipação municipal; divisão territorial; disputas políticas; legalidade.

Resumen: En Brasil, con la promulgación de la Constitución Federativa de 1988, los criterios para la creación de nuevas municipalidades pasaron a ser de responsabilidad de los Estados Federados. Estos criaron reglas que facilitaron la creación de estas unidades políticas, lo que contribuyó para la intensificación de desmembramientos en todo el país. Como consecuencia de ello, fue aprobada por el Congreso Nacional la Emenda Constitucional número 15/1996, que impidió que municipios fuesen creados hasta que hubiese nueva reglamentación federal. Los nuevos municipios creados sin la existencia de una ley federal fueron contestados judicialmente. El trabajo aquí presentado busca desvelar como pudo nuevos municipios ser creados e instaurados sin apoyo en aspectos legales, y por cuales motivaciones el Poder Judicial mantuvo su existencia. La instauración de estos municipios, tema polémico en lo cual no hay concordancia, desvela embates políticos, de relaciones de poder y de concepciones de Estado que llevan a la reflexión sobre el sentido de la división territorial en Brasil.

Palabras Clave: emancipación municipal; división territorial; disputas políticas; legalidad.

Abstract: The Brazilian Federal Constitution of 1988 attribute to the Federated states to define the criteria for the creation of new municipalities. Therefore, the states' rules facilitate the creation of these political units, which contributed to the 
dismembering intensification throughout the country. Because of this, it was approved the Constitutional Amendment 15/1996 which prevented municipalities from being created until new Federal regulations, and those created without the legal regulation were judicially contested. This work intends to uncover how municipalities could be created and installed since then, without legal support, and for what reasons the Brazilian judiciary maintained its existence. Controversial The establishment of these municipalities reveals political disputes, power relations, and conceptions of State that lead to reflection on the meaning of the territorial division in Brazil.

Keywords: municipal emancipation; territorial division; politic disputes; legality.

\section{INTRODUÇÃO}

A criação de municípios, no Brasil, tem sido constante, desde o início da ocupação do território. Ele foi a primeira forma de governo em 1532. A divisão territorial em escala local precede, portanto, as outras escalas, pois os estados brasileiros têm sua origem com a criação das capitanias (1534) e o Governo Central com a criação do Governo Geral (1549).

Ao se observar a história da criação de municípios nota-se que, na Colônia, o movimento de conquista do território impunha uma dinâmica espacial previamente definida, baseada numa geopolítica, cujo objetivo maior era a estratégia de ocupação e de proteção do território. Os municípios do período possuíam muita autonomia e seus mandantes um enorme poder, formas autônomas de governo num território vasto e sem comunicação interna.

No Império, o governo local foi entendido como entidade administrativa. As unidades políticas locais foram unificadas por uma força centrípeta, garantindo a integridade do poder político disperso durante o período anterior. Dessa forma, aos municípios se impôs a simetria - força centralizadora - produzida por uma ação verticalizada de controle e normatização do poder central (CIGOLINI, 2015).

Na República, segundo Cigolini (2014), a malha municipal avançou na medida da ocupação do território e sua configuração resultou de ações espontâneas, dirigidas ou induzidas. O papel dos municípios, desde a declaração da República, foi se alternando entre descentralização e centralização, segundo as conjunturas específicas de mudança do poder central, que entendia essa unidade política de diferentes formas. Com a República o município se insere no debate federativo, objeto de disputa e tensão permanente entre forças centralizadoras e descentralizadoras. Com a redemocratização do país, em 1985, e com a promulgação da Constituição de 1988, o município foi elevado a ente Federativo com autonomia plena, resultado da vitória das forças descentralizadoras sobre a centralização militar, período a partir do qual há um intenso processo de criação de novos municípios.

Nota-se que o papel do município inserido sistema político brasileiro varia no decorrer do tempo. Mas o que há de comum, sobre ele, em toda história brasileira é o fato de que, independente do o regime político ou as funções do governo local, sempre ocorreu a divisão do território em municípios, em maior ou menor intensidade. Porém, em oposição a continuidade da compartimentação do território em municípios, em 1996 
o Congresso Nacional aprovou a Emenda Constitucional número 15, que manteve nos estados parte da responsabilidade pela regulamentação das emancipações, porém criou algumas regras que as dificultavam. Após a aprovação da emenda foram instalados 539 municípios, que haviam sido criados antes disso. Mas, também foram criados e instalados dezenas de municípios depois de promulgada a citada Emenda.

A constitucionalidade da criação dessas municipalidades passou a ser questionada por diversas instituições e atores políticos, o que colocou esses municípios, que já exerciam suas funções legais, sob a ameaça de retornarem à categoria de localidades não emancipadas.

A discussão que surgiu a partir dos questionamentos sobre a existência de tais municípios demonstrou que a divisão territorial tem capacidade de envolver diversas esferas de poder. Este artigo procura elucidar quais mecanismos legais validaram os municípios criados sem amparo legal. Em consequência dessa abordagem, o texto não procura entender causas, consequências e os impactos da criação dos municípios no território, pois esse conteúdo está amplamente presente na literatura. No entanto nenhum estudo procurou entender como os mecanismos legais e as posições do poder Judiciário, Legislativo e Executivo permitiram a legalização dos 59 municípios criados irregularmente.

Trazemos aqui a discussão contemporânea sobre essa problemática, enfocando especificamente no conflito e na solução encontrada pelos atores políticos em relação aos municípios criados em flagrante ilegalidade e fazemos uma reflexão mais ampla sobre o sentido das compartimentações territoriais.

\section{UM BREVE DEBATE SOBRE O MUNICÍPIO}

Para Castro (2005, p. 135) os municípios brasileiros podem ser entendidos como

“[...] recortes federativos com elevado grau de autonomia, o que significa que possuem seus próprios recursos e atribuições. Estes também aparecem como escala política ou território político, sendo um distrito eleitoral que elege prefeitos e vereadores, além da realização de outras eleições informais, de grande importância para a sociedade local e o território".

Usando o conteúdo da citação como referência, pode-se assumir, do ponto vista conceitual, que o município é um espaço recortado e gerido com base em relações de poder, sendo um território, de caráter formal, com autonomia e elevada capacidade de impor ações sobre o espaço. Por território se entende um espaço criado e delimitado a partir de relações de poder, nos termos evidenciados por Souza (2013).

Nos municípios habitamos e exercemos nossa cidadania. Também nele buscamos serviços, e onde são concretizadas as políticas públicas. Segundo Corralo (2015), como ente Federado, ele possui várias formas de autonomia: auto-organizatória, administrativa, legislativa, financeira e política, que se refletem nas competências, isto é, naquilo que o município pode efetivamente fazer. Sendo seu atributo exclusivo, segundo a Constituição de 1988:

- Legislar sobre assuntos de interesse local; 
- Suplementar a legislação federal e a estadual no que couber; instituir e arrecadar os tributos de sua competência, bem como aplicar suas

- Rendas, sem prejuízo da obrigatoriedade de prestar contas e publicar balancetes nos prazos fixados em lei;

- Criar, organizar e suprimir distritos, observada a legislação estadual;

- Organizar e prestar, diretamente ou sob regime de concessão ou permissão, os serviços públicos de interesse local, incluído o de transporte coletivo, que tem caráter essencial;

- Manter, com a cooperação técnica e financeira da União e do Estado, programas de educação infantil e de ensino fundamental;

- Prestar, com a cooperação técnica e financeira da União e do Estado, serviços de atendimento à saúde da população;

- Promover, no que couber, adequado ordenamento territorial, mediante

- Planejamento e controle do uso, do parcelamento e da ocupação do solo urbano;

- Promover a proteção do patrimônio histórico-cultural local, observada a legislação e a ação fiscalizadora federal e estadual.

Prado Junior já chamava a atenção para a autonomia do município brasileiro do período colonial “Grande parte dos negócios públicos, inclusive matérias relevantes de caráter geral, eram tratadas e resolvidas nas câmaras, que chegaram num momento a legislar sobre quase todos os assuntos governamentais". (1969, p. 51). Como se observa, há muito tempo o espectro de ação e capacidade de decisão dos governos municipais é amplo.

A Constituição de 1988 também definiu que cada estado elaboraria suas próprias leis acerca da emancipação de localidades. A partir disso muitos estados passaram a criar leis consideradas facilitadoras das emancipações. Com isso, de 3.974 municípios, em 1980, o Brasil passou a ter 4.629, em 1996. Grande parte da emancipação de localidades, que se tornaram municípios, ocorreu no final dos anos 80 e início dos anos $90^{1}$.

Para Tomio (2005) as emancipações podem se vistas de maneira negativa ou positiva dependendo do ponto de vista. Nos pequenos municípios ela pode se vista como uma forma de impedir o êxodo através da geração de empregos (públicos) e uma maior oferta de serviços, podendo ser vista como uma política progressiva de distribuição de renda e preventiva do inchaço dos centros urbanos.

No passado recente a criação de municípios já foi definida como problema e como solução. As instituições estimularam ou reprimiram as emancipações numa oscilação que não variou, necessariamente, com o regime político. Em virtude disto, não me surpreenderia se num espaço curto de tempo uma nova institucionalidade descentralizadora substituísse a hegemonia centralista atual. (TOMIO, 2005, p.116).

1 Quando houve o salto expressivo dessas unidades políticas, numerosos estudos surgiram para explicar o fenômeno, tais como Mello (1992; 2001), Noronha (1997), Shikida (1998), Cigolini (2014; 2015), Gomes e Mac Dowell (2000), Lima (2000), Ayres (2001), Cataia (2011; 2013), Caldas (2002), Motta Junior (2002), Tomio (2002), Baltar e Baltar (2018), Pinto (2003), Fávero (2004), Bremaeker (1992; 1996), Bezerra (2006; 2016), Alves (2006), Wanderley (2007), Brandt (2010), Souza (2010), Azevedo (2013), Silva e Rocha (2012), Nascimento (2014), Almeida (2014), Souza (2015), entre outros. 
Geralmente argumenta-se que um dos principais impactos dos desmembramentos é o aumento de gastos com cargos públicos nos novos municípios, além da falta de planejamento que faz surgir municípios pequenos sem rendimento suficiente para se sustentar. Para Castro (2005) esses argumentos usados na discussão sobre emancipações são em parte verdadeiros, porém não constituem uma verdade geral. Os mais usados são aqueles que se referem aos altos gastos com a máquina política e administrativa municipal. Porém esses argumentos não levam em consideração que os municípios também são lugares de aprendizado da cidadania e da democracia.

Na análise de Cigolini (2001; 2017), as causas e consequências da criação de municípios, de forma detalhada, dão a dimensão de como as ciências sociais trataram academicamente essa temática. Pode-se afirmar que o tema está relativamente bem compreendido, embora não esgotado, sendo controverso. Mostra também como a força política é evidente e se revela na criação, em muitos estados, de novos municípios à revelia da Legislação Federal.

\section{AS EMANCIPAÇÕES MUNICIPAIS E A EMENDA CONSTITUCIONAL 15/96.}

Embora a Emenda Constitucional 15/1996 tenha mantido sob a responsabilidade dos estados a elaboração das leis referentes aos desmembramentos, criou regras como EVM (Estudo de Viabilidade Municipal) e exigiu que o necessário plebiscito fosse estendido a toda população, inclusive a do município de origem, e não apenas à população do distrito envolvido no processo. A Emenda passou a ser válida após sua publicação, porém seria necessária uma Lei Complementar para regulamentar as exigências contidas na mesma, o que levou a Câmara e o Senado Federal a aprovar o Projeto de Lei 98/2002, de regulamentação definitiva da Emenda Constitucional 15/96, que já tramitava há cinco anos. Vetada, no entanto, pela Presidência da República, por ser considerada como um facilitador da multiplicação do número de municípios. Em 2014 surgiu outro Projeto de Lei com a mesma proposta do anterior, o PL 104/2014. Esse projeto foi aprovado no Congresso, como o anterior, porém novamente vetado pela Presidência da República, que tornou a alegar que a lei poderia levar a um novo surto de emancipações. Isso na verdade não se traduzia pois, como demonstraram Cigolini e Matiolo (2014), essa nova lei não produzia estoque de áreas emancipáveis, uma vez que poucos distritos ou localidades conseguiriam atender os requisitos que ela impunha.

Desse modo, desde a promulgação da Emenda Constitucional 15/1996, até o presente momento, se passaram mais de vinte anos sem uma lei para regulamentar as emancipações. Mas nesse tempo, processos de criação de municípios continuaram a acontecer amparados apenas em leis estaduais.

Conforme se observa na Tabela 1, no Rio Grande do Sul foram criados 29 municípios; em Mato Grosso, 15; e em Goiás, quatro. No Piauí e Bahia criou-se dois municípios cada e em Alagoas apenas um. Também no Espírito Santo, Tocantins, Pará, Rio de Janeiro, Rio Grande do Norte e Mato Grosso do Sul foram criados um município em cada. 
A grande maioria desses municípios teve sua instalação no ano de 2001, após as eleições municipais ocorridas em 2000, com exceção de Sapucaia (Pará) e Barra do Ouro (Tocantins) instalados em 1997; Aroeiras do Itaim (Piauí), Figueirão (Mato Grosso do Sul), Ipiranga do Norte e Itanhangá (Mato Grosso) que tiveram sua instalação no ano de 2005.

Tabela 1: Dados geográficos dos municípios analisados, criados até o ano de 2005*.

*Exceto Sapucaia (PA) e Barra do Ouro (TO).

\begin{tabular}{|c|c|c|c|c|}
\hline Nome e localização & Área $\left(\mathrm{Km}^{2}\right)$ & População urbana & População rural & População Total \\
\hline Aceguá (RS) & $1.549,4$ & 1.059 & 3.335 & 4.394 \\
\hline Almirante Tamandaré do Sul (RS) & 265,4 & 839 & 1.228 & 2.067 \\
\hline Aroeiras do Itaim (PI) & 257,1 & 238 & 2.202 & 2.440 \\
\hline Arroio do Padre (RS) & 124,3 & 454 & 2.276 & 2.730 \\
\hline Barrocas (BA) & 201,0 & 5.695 & 8.496 & 14.191 \\
\hline Boa Vista do Cadeado (RS) & 701,1 & 472 & 1.969 & 2.441 \\
\hline Boa Vista do Incra (RS) & 503,5 & 724 & 1.701 & 2.425 \\
\hline Bom Jesus do Araguaia (MT) & $4.274,2$ & 2.648 & 2.666 & 5.314 \\
\hline Bozano (RS) & 201,0 & 629 & 1.571 & 2.200 \\
\hline Campo Limpo de Goiás (GO) & 159,6 & 5.289 & 952 & 6.241 \\
\hline Canudos do Vale (RS) & 81,9 & 411 & 1.396 & 1.807 \\
\hline Capão Bonito do Sul (RS) & 527,1 & 499 & 1.255 & 1.754 \\
\hline Capão do Cipó (RS) & $1.008,7$ & 519 & 2.585 & 3.104 \\
\hline Colniza (MT) & $27.924,5$ & 14.987 & 11.394 & 26.381 \\
\hline Conquista D'Oeste (MT) & $2.672,2$ & 2.053 & 1.332 & 3.385 \\
\hline Coqueiro Baixo (RS) & 112,3 & 282 & 1.246 & 1.528 \\
\hline Coronel Pilar (RS) & 105,4 & 174 & 1.551 & 1.725 \\
\hline Cruzaltense (RS) & 166,9 & 489 & 1.652 & 2.141 \\
\hline Curvelândia (MT) & 359,8 & 2.894 & 1.972 & 4.866 \\
\hline Figueirão (MS) & $4.882,9$ & 1.530 & 1.398 & 2.928 \\
\hline Forquetinha (RS) & 93,6 & 468 & 2.011 & 2.479 \\
\hline Gameleira de Goiás (GO) & 592,0 & 1.094 & 2.181 & 3.275 \\
\hline Governador Lindenberg (ES) & 359,6 & 4.226 & 6.643 & 10.869 \\
\hline Ipiranga de Goiás (GO) & 241,3 & 1.272 & 1.572 & 2.844 \\
\hline Ipiranga do Norte (MT) & $3.467,0$ & 3.475 & 1.648 & 5.123 \\
\hline Itanhangá (MT) & $2.898,1$ & 3.171 & 2.105 & 5.276 \\
\hline Itati (RS) & 206,9 & 212 & 2.372 & 2.584 \\
\hline Jacuizinho (RS) & 338,5 & 562 & 1.945 & 2.507 \\
\hline Jequiá da Praia (AL) & 351,6 & 2.879 & 9.150 & 12.029 \\
\hline Jundiá (RN) & 44,6 & 960 & 2.622 & 3.582 \\
\hline Lagoa Bonita do Sul (RS) & 108,5 & 384 & 2.278 & 2.662 \\
\hline Lagoa Santa (GO) & 458,9 & 776 & 478 & 1.254 \\
\hline Luís Eduardo Magalhães (BA) & $3.941,1$ & 54.881 & 5.224 & 60.105 \\
\hline Mato Queimado (RS) & 114,6 & 479 & 1.320 & 1.799 \\
\hline Mesquita (RJ) & 39,1 & 168.376 & - & 168.376 \\
\hline Nova Nazaré (MT) & $4.038,1$ & 1.119 & 1.910 & 3.029 \\
\hline Nova Santa Helena (MT) & $2.205,1$ & 1.988 & 1.480 & 3.468 \\
\hline Novo Santo Antônio (MT) & $4.393,8$ & 1.346 & 659 & 2.005 \\
\hline
\end{tabular}


conclusão

\begin{tabular}{|c|c|c|c|c|}
\hline Nome e localização & Área $\left(\mathrm{Km}^{2}\right)$ & População urbana & População rural & População Total \\
\hline Novo Xingu (RS) & 80,6 & 554 & 1.203 & 1.757 \\
\hline Pau D'Arco do Piauí (PI) & 430,8 & 556 & 3.201 & 3.757 \\
\hline Paulo Bento (RS) & 148,4 & 594 & 1.602 & 2.196 \\
\hline Pedras Altas (RS) & $1.377,4$ & 768 & 1.444 & 2.212 \\
\hline Pinhal da Serra (RS) & 437,4 & 478 & 1.652 & 2.130 \\
\hline Quatro Irmãos (RS) & 268,0 & 916 & 859 & 1.775 \\
\hline Rolador (RS) & 295,0 & 608 & 1.938 & 2.546 \\
\hline Rondolândia (MT) & $12.670,8$ & 950 & 2.654 & 3.604 \\
\hline Santa Cecília do Sul (RS) & 199,4 & 480 & 1.175 & 1.655 \\
\hline Santa Cruz do Xingu (MT) & $5.651,7$ & 1.251 & 649 & 1.900 \\
\hline Santa Margarida do Sul (RS) & 955,3 & 552 & 1.800 & 2.352 \\
\hline Santa Rita do Trivelato (MT) & $4.728,2$ & 1.367 & 1.124 & 2.491 \\
\hline Santo Antônio do Leste (MT) & $3.600,7$ & 2.119 & 1.635 & 3.754 \\
\hline São José do Sul (RS) & 59,0 & 720 & 1.362 & 2.082 \\
\hline São Pedro das Missões (RS) & 80,0 & 532 & 1.354 & 1.886 \\
\hline Serra Nova Dourada (MT) & $1.500,4$ & 813 & 552 & 1.365 \\
\hline Tio Hugo (RS) & 114,2 & 1.164 & 1.560 & 2.724 \\
\hline Vale de São Domingos (MT) & $1.932,8$ & 713 & 2.339 & 3.052 \\
\hline Westfalia (RS) & 64,0 & 1.130 & 1.663 & 2.793 \\
\hline
\end{tabular}

Fonte: IBGE, 2010.

Esses dados ajudam a ilustrar as características desse conjunto de municípios. Chama atenção, em primeiro lugar, a questão populacional. Sete deles possuem mais de dez mil habitantes, destacando-se o município de Mesquita (RJ), com 168.376 hab., população essa atípica em relação ao padrão dos novos municípios criados no Brasil. Tal situação decorre de sua localização geográfica, emancipado que foi em continuidade da área urbana de Nova Iguaçu, na Baixada Fluminense, uma área densamente povoada. Após esse, em classificação decrescente estão Luiz Eduardo Magalhães (BA) e Colniza (MT). O primeiro teve um crescimento exponencial devido a expansão da pecuária e agricultura (soja) na região Oeste da Bahia, e o segundo tem seu crescimento populacional baseado na mineração e agricultura naquela região de Mato Grosso.

Após tais exceções, quatro municípios apresentam entre cinco e dez mil habitantes, 12 entre três e cinco mil habitantes e 34 até três mil habitantes. Isso mostra que a criação de novos municípios amplia, sobremaneira, a geração de pequenas cidades. Chama atenção o estado do Rio Grande do Sul que dos 29 municípios criados, tem apenas um com mais que três mil habitantes. Em relação a área territorial, o padrão segue muito parecido com aquele já existente na configuração da malha municipal brasileira - municípios em áreas de menor densidade e expansão agrícola, como Colniza e Rondolândia, em Mato Grosso, possuem grande extensão territorial (27.924,5 e 12.670,80 Km², respectivamente) enquanto aqueles localizados em áreas mais densamente povoadas, cuja malha municipal já é igualmente mais densa, tem pequena extensão territorial, como é o caso de Mesquita 
(RJ), que possui apenas $39,10 \mathrm{Km}^{2}$. Em relação a distribuição populacional, é interessante notar que na maioria dos municípios, a população rural predomina sobre a urbana.

Como esses municípios começaram a ter sua legitimidade questionada por diversos órgãos e autoridades, que protocolaram diversas Ações de Inconstitucionalidade junto ao Supremo Tribunal Federal (STF), ficaram sob risco de retornarem à condição de distritos. Embora o município de Jequiá da Praia (AL) não se enquadre nessa situação específica, pois teve sua lei de criação publicada anteriormente a promulgação da emenda constitucional 15/1996, esse município teve seu processo de criação questionado através da ADIN - Ação Direta de Inconstitucionalidade, protocolada pelo Partido Popular Socialista (PPS), alegando a ausência prévia da consulta pública via plebiscito estendido as populações dos entes políticos envolvidos. O caso dos municípios criados no Rio Grande do Sul se enquadra na mesma situação que Jequiá da Praia, dada à publicação das leis de criação anteriores a promulgação da Emenda Constitucional 15/1996. Porém esses municípios tiveram sua lei de criação questionada através da ADIN protocolada pelo Governador do Rio Grande do Sul, também alegando a ausência do plebiscito estendido a toda população dos entes políticos envolvidos.

O município de Luís Eduardo Magalhães (BA) teve a publicação de sua lei de criação em 30/03/ 2000 e por isso o PT (Partido dos Trabalhadores) propôs a ADIN 2.240/BA. No julgamento dessa ação o STF entendeu como inconstitucional a lei de criação do município, mas reconheceu o interesse social em sua continuidade e utilizou do princípio da segurança jurídica, como mostra a nota jurídica da Confederação Nacional de Municípios.

Utilizando a técnica alternativa de ponderação entre o princípio da nulidade da lei, de um lado, e princípio da segurança jurídica, de outro, entendeu o STF que a lei é inconstitucional, mas, aplicando o art. 27 da Lei 9.868/1999 e, tendo em vista razões de segurança jurídica e excepcional interesse social, apesar de inconstitucional por violar o art. 18, $4^{\circ}$, deverá continuar vigorando por 24 meses (CNM, 2008, p.4).

Essa decisão da Suprema Corte admite a nulidade da lei de criação de Luís Eduardo Magalhães, porém ao se utilizar desse princípio manteve a sua vigência por 24 meses, prazo que deu ao Congresso Nacional para regulamentar o tema, através de lei específica. A decisão influenciou nos demais julgamentos das ações de inconstitucionalidade, sendo que a tese adotada no caso citado foi usada como padrão nos demais.

Com a imposição de um prazo ao Congresso Nacional, o Supremo Tribunal Federal pretendia 'forçar' o mesmo a regulamentar o dispositivo constitucional que tratava da criação de municípios. Caso o Congresso não aprovasse tal regulamentação, os municípios em questão deixariam de existir.

Segundo Vieira e Brasil (2007), na decisão dessa ADIN alegou-se que a criação dos municípios foi realmente uma violação à regra, porém a falta de atitude em relação à aprovação da lei complementar para a Emenda Constitucional 15/1996 foi considerada como omissão, o que legitimaria os processos de criação de municípios ocorridos na ausência da regulamentação. 
A decisão política da criação do Município violou a regra constitucional, mas foi afirmada, produzindo todos os efeitos dela decorrentes. O preceito veiculado pelo parágrafo $4^{\circ}$ do art. 18 da Constituição visa a impedir a criação, a incorporação, a fusão e o desmembramento de Municípios fora de período determinado por lei complementar federal. Como o Legislativo omitiu-se, deixando de produzir essa lei complementar, e o ente federativo surgiu, existindo como tal, a aplicação do preceito para que se declare a inconstitucionalidade do ato legislativo estadual e a inconstitucionalidade institucional do Município agravará a moléstia do sistema. Se da aplicação de uma norma resulta um desvio de finalidade a que ela se destina, ela finda por não cumprir o seu papel, ela deforma. Precisamente isso se daria no caso, se a autonomia do ente federativo viesse a ser anulada (VIEIRA; BRASIL, 2007, p. 309).

Como se vê, o STF validou os novos municípios baseado na autonomia estadual sobre o assunto. Essa ação do STF é considerada por diversos juristas como uma interferência direta do Poder Judiciário no Poder Legislativo, o que viria a ferir a separação de poderes. Como resposta a essa interferência, o Congresso aprovou a Emenda Constitucional 57/2008 que, em seu artigo $1^{\circ}$., convalidou os atos de criação, fusão, incorporação e desmembramentos cuja lei tenha sido publicada até 31 de dezembro de 2006 e que tenham atendido os requisitos das leis referentes ao tema do seu respectivo estado. Assim o Congresso eliminou a possibilidade de extinção desses municípios após prazo dado pelo STF.

A promulgação enfim dessa Emenda pôs fim a situação dos 57 municípios que tiveram sua criação contestada. Porém, essa ação do Congresso Nacional é criticada por tratar-se apenas de um paliativo, já que mantém uma situação problemática, que perdura mais de vinte anos, sem que os três poderes entrarem em um consenso sobre uma possível solução. O tema criação de municípios revelou, nesse caso, um embate que envolve o Executivo, o Legislativo e o Judiciário.

Embate esse, entretanto, que não é novo, pois Maia em 1883 informa que, na Colônia, muitas municipalidades também foram criadas pela vontade local, à revelia das autoridades centrais, que somente ratificavam a iniciativa, citando o seguinte exemplo

Os antigos habitantes de Pindamonhangaba, recusando obediência à vila de Taubaté, subornaram o ouvidor de São Paulo, que por casualidade estava presente, e em uma só noite levantaram o pelourinho, elegendo juízes e oficiais da Câmara. Queixandose os de Taubaté a S. Majestade, e defendendo-se perante ela os novos munícipes, baixou carta régia de 10 de julho de 1705 que confirmou o ato popular, dando a vila por aclamada. (1883, p.72).

Nunes, ainda em 1920, cita que tiveram origem semelhante os municípios de Campos e Paraty (RJ).

Os exemplos acima citados denotam a repetição da história, mostrando a relação conflituosa do município com o Poder Central, quando se trata de quem decide quais lugares têm o direito a autonomia. Isso parece ser uma discussão ainda pendente na geografia, que tem se furtado a discutir a autonomia dos lugares e as condições pelas quais ela possa existir. 


\section{CONSIDERAÇÕES FINAIS}

A criação de municípios apresenta diversas peculiaridades na discussão sobre a divisão territorial brasileira. Uma delas é o significado do município, enquanto governo local que desempenha um papel na organização territorial de um país de tamanha extensão, além da importância dessa unidade no dia a dia de seus habitantes. É no município que os problemas cotidianos são percebidos de modo mais agudo e é onde a ação política se concretiza, sendo um espaço de aprendizado democrático, com todas as virtudes e problemas que isso implica.

Outra se refere a intensidade de ocorrência dos processos de emancipação, sendo que nas décadas de 80 e 90 o surto emancipacionista fez com que os atores políticos nacionais assumissem uma postura avessa a ocorrência desse processo, legislando de maneira a que fosse interrompido. Na escala nacional isso foi uma solução ao conter, embora não tenha impedido, o acirramento pela disputa de recursos, uma vez que os pequenos municípios são altamente dependentes de repasses do governo federal através do Fundo de Participação dos Municípios - mais municípios significa mais atores para os mesmos recursos, que são finitos. Do ponto de vista da política local e das centenas de localidades sem autonomia e acesso a recursos, o cerceamento da possibilidade de emancipação, por outro lado, se torna um problema.

Outro aspecto está relacionado com a força desses processos. Não há na história do Brasil nenhum período político em que municípios deixaram de ser criados. Mesmo em período de forte centralização de poder, como no Estado Novo, as emancipações continuaram. No recente cenário político e institucional adverso, criado pela Emenda 15/1996, municípios também foram criados e instalados, ainda que de maneira ilegal, gerando conflitos adicionais envolvendo as variadas esferas do poder.

No julgamento das ações protocoladas a partir dessa situação, o STF reconheceu a função social que esses municípios desempenham e baseia suas decisões nisso, além de responsabilizar o Congresso Nacional pela negligência em regulamentar a lei com as normas para emancipações. Como resposta, o Congresso procurou regulamentar por duas vezes a Emenda Constitucional 15/1996, ambas vetadas pela Presidência da República. Há assim um evidente conflito entre os três poderes da República. Nem mesmo dentro de um mesmo Poder, no caso o Executivo, há consenso, pois na escala dos Estados Federados e na escala local, dos municípios, existe um movimento forte favorável às emancipações, enquanto na escala Federal, há um movimento contrário. Isso gera uma situação de incerteza em relação a esses processos, que propícia a manutenção de potenciais conflitos prejudicando o ordenamento político brasileiro.

A discussão acerca da divisão do território brasileiro está em pleno curso e as opiniões sobre a criação de novos municípios podem mudar, de acordo com o ambiente político estabelecido. Porém, a criação de unidades políticas, independentemente da escala de compartimentação, é um fenômeno inerente à história social. As partições são um elemento central do estabelecimento da vida comunitária, que requer a divisão territorial como forma de organização política, pois desse modo é possível estruturar e organizar as 
relações internas dos grupos e, ao mesmo tempo, permite o reconhecimento, pelo outro, da existência política dessa comunidade. Desse modo, tanto do ponto de vista interno como externo, o território expressa a possibilidade da organização política, o que proporciona certo nível de autonomia ao grupo e a inserção no sistema de relações interestatais. Como organizar esse processo, os atores e interesses das múltiplas escalas nele envolvidos, constitui um desafio que ainda está longe de ser vencido.

O Brasil, atualmente, tem 5.570 unidades de governo local e o potencial de criação de novos municípios dependerá, essencialmente, da criação de novas normas, que possibilitarão o estoque de áreas emancipáveis. São os requisitos definidos pela legislação que qualificarão o território das vilas e localidades, definindo-as como potenciais municípios ou não. Todo esse debate acerca da criação dos municípios continua aberto e sem previsões de se encerrar.

\section{REFERÊNCIAS}

ALVES, Alessandro C. O Processo de Criação de Municípios no Paraná: as instituições e a relação executivo e legislativo pós 1988. Revista Paranaense de Desenvolvimento, v. 111, p. 47-72, 2006.

ALMEIDA, Katia R. Emancipação Municipal e transformações socioespaciais: os casos de Bom Jesus da Serra e Caetanos. Salvador, 2014. Dissertação (Mestrado em Geografia) - Universidade Federal da Bahia, UFBA.

AYRES, Érico. Processo e política atual de desmembramento municipal no Maranhão. São Paulo, 2001. Tese (Doutorado em Estruturas Ambientais Urbanas) - Universidade de São Paulo, USP.

AZEVEDO, Daniel A. de. Fragmentação e divisão territorial: um debate para além de ideologias. In: FONSECA, Antonio A.M. da; PERTILE, Noeli; CALDAS, Alcides dos Santos; BRITO, Cristovão (Orgs.). Estado, Território e a Dinâmica das fronteiras: reflexões e novos desafios. Salvador: JM, 2013. v. 1, p. 53-72.

BALTAR, Cláudia S.; BALTAR, Ronaldo. Debatendo a criação de municípios na contemporaneidade: considerações a partir da urbanização e da participação dos pequenos municípios no Brasil e no Paraná. Revista de Geografia e Ordenamento do Território, p. 71-107, 2018.

BEZERRA, Josineide da Silva. O território como um trunfo: um estudo sobre a criação de municípios na Paraíba (anos 90). João Pessoa, 2006. Dissertação (Mestrado em Geografia) - Universidade Federal da Paraíba, UFP.

BEZERRA, Josineide da Silva. Novos Municípios, Velhas políticas: Práticas de emancipação distrital e estratégicas de reprodução política na Paraíba (1951-1965). Recife, 2016. Tese (Doutorado em História) Universidade Federal de Pernambuco, UFPE.

BRANDT. Cristina T. A criação de municípios após a constituição de 1988: o impacto sobre a repartição do FPM e a emenda constitucional no 15 de 1996. Brasília: Congresso Nacional, 2010. (Estudos Técnicos).

BREMAEKER, Francois E.J. de. Os novos municípios: surgimento, problemas e soluções. Rio de Janeiro: IBAM, 1992. (Estudos Especiais, 4)

BREMAEKER, Francois. E. J. de. Limites à criação de novos municípios: a Emenda Constitucional n. ${ }^{\circ} 15$. Revista de Administração Municipal, v. 43, n. ${ }^{\circ}$ 219, p. 118- 128. Rio de Janeiro: IBAM, 1996.

CALDAS, Eduardo L. O processo de criação de municípios no Estado de São Paulo entre 1991 e 1996: uma abordagem institucionalista. São Paulo, 2002. Dissertação (Mestrado em Ciência Política) - Fundação Getúlio Vargas, FGV.

CATAIA, Márcio A. Território usado e Federação: novos agentes e novos pactos. In: DANTAS, A.; TAVARES, M.A.A. (Org.). Lugar-mundo: perversidades e solidariedades. Encontros com o pensamento de Milton Santos. Natal: Ed. UFRN, 2011. p. 101-119. 
CATAIA, Márcio A. Território usado e federação: articulações possíveis. Educ. Soc., v.34, n.125, p. 11351151, 2013.

CASTRO, Iná E. de. Geografia e política: território, escalas de ação e instituições. Rio de Janeiro: Bertrand Brasil, 2005.

CIGOLINI, Adilar A. Território e fragmentação: análise do processo recente de criação de municípios no Paraná. RA'E'GA, v.5, n.47, p. 48-66, 2001.

CIGOLINI, Adilar A. Ocupação do território e criação de municípios no período republicano brasileiro. Biblio 3w, Barcelona, v. 19, p. 1101-1105, 2014.

CIGOLINI, Adilar A. Ocupação do território e a criação de municípios no período imperial brasileiro. Mercator, v. 14, p. 7-19, 2015.

CIGOLINI, Adilar A. Análise da literatura explicativa sobre o processo contemporâneo da criação de municípios no Brasil. Revista de Estudios Brasileños, v. 4, p. 95-107, 2017.

CIGOLINI, Adilar A.; MATIOLO, E. A nova legislação e a potencialidade de criação de novos municípios no Brasil. In: CONGRESSO BRASILEIRO DE GEOGRAFIA POLÍTICA, GEOPOLÍTICA E GESTÃO DO TERRITÓRIO. 1, 2014, Porto Alegre. Anais... p. 508-519.

CORRALO, Giovani. O poder municipal na federação brasileira: reflexão sobre a autonomia municipal e o federalismo. Revista História: Debates e Tendências, v. 15, n. 1, 2015.

CNM - Confederação Nacional de Municípios. Considerações Jurídicas Sobre o Tema das Emancipações. Brasília, 2008. Disponível em:http://portal.cnm.org.br/sites/5800/5840/historicodasemancipacoes.pdf Acesso em: 29 jul. 2018.

GOMES, Gustavo M.; MAC DOWELL, Maria C. Descentralização política, federalismo fiscal e criação de municípios: o que é mau para o econômico nem sempre é bom para o social. Brasília: IPEA, 2000. (Texto para discussão, 706).

FÁVERO, Edison. Desmembramento territorial: o processo de criação de municípios - avaliação a partir de indicadores econômicos e sociais. São Paulo, 2004. Tese (Doutorado em Engenharia Urbana) - Escola Politécnica da Universidade de São Paulo, USP.

LIMA, Maria H.P. O processo de emancipação municipal no Estado do Espírito Santo. Rio de Janeiro, 2000. Dissertação (Mestrado em Geografia) - Universidade Federal do Rio de Janeiro, UFRJ.

MAIA, João de Azevedo Coutinho. O município - Estudos sobre a administração local. Rio de Janeiro, 1883.

MELLO, Diogo L. de. A multiplicação de municípios no Brasil. Revista de Administração Municipal, v. 39. n. 203, p. 23-28, 1992.

MELLO, Diogo L. Governo e administração municipal: a experiência brasileira. RAP, Revista de Administração Pública, n. 35, n.2, p. 79-96, 2001.

MOTTA JUNIOR, Vidal da. A criação de pequenos municípios como um fenômeno da descentralização política: o caso de Itaoca-SP. São Carlos, 2002. Dissertação (Mestrado em Ciências Sociais) - Universidade Federal de São Carlos, UFSCar.

NASCIMENTO, Thamara N.A.; SANTOS, Damaris; SANTOS, Elisana. Criação de Municípios por Emancipação de Distritos - Terra Nova do Norte. CONGRESSO BRASILEIRO DE GEÓGRAFOS. 7, 2013, Vitória. Anais ... Vitória: UFES/ AGB, 2014.p.

NORONHA, Rudolf. Emancipação municipal: implicações espaciais da divisão político-administrativa do território fluminense. Rio de Janeiro, 1997. Dissertação (Mestrado em Geografia) - Universidade Federal do Rio de Janeiro, UFRJ.

NUNES, José de Castro. Do Estado Federado e sua Organização Municipal. Rio de Janeiro: Biblioteca do Pensamento Político Republicano, 1920.

PRADO JUNIOR, Caio. História econômica do Brasil. 11.ed. São Paulo: Brasiliense, 1969. 
PINTO, Georges J. Do sonho à realidade: Córrego Fundo-MG: fragmentação territorial e criação de municípios de pequeno porte. Uberlândia, 2003. Dissertação (Mestrado em Geografia) - Universidade Federal de Uberlândia, UFU.

SILVA, Fernando; ROCHA, Isa. Emancipação municipal em Santa Catarina. Geosul, v. 27, n. 53, p. 115-138, 2012.

SHIKIDA, Cláudio D. A economia política da emancipação de municípios em Minas Gerais. Brasília: ESAF, 1998.

SOUZA, M.J.L. de. O território: sobre espaço e poder, autonomia e desenvolvimento. In: CASTRO, Iná E. de; COSTA, P. C.; CORREAA, Roberto L. (Orgs.). Geografia: conceitos e temas. 5.ed. Rio de Janeiro: Bertrand Brasil, 2013.

SOUZA, Romilda A. Movimento em Prol da Emancipação do Entroncamento de Jaguaquara-BA: Uma Análise da Sua Dinâmica Sócio-territorial. Enciclopédia Biosfera, v. 6, n.10, p. 2010.

SOUZA, Romilda A. Análise das estratégias para emancipação municipal: um estudo comparado entre distritos emancipados e não emancipados. Salvador, 2015. Tese (Doutorado em Geografia) - Universidade Federal da Bahia, UFBA.

TOMIO, Fabrício R. de Lima. Autonomia municipal e criação de governos locais: a peculiaridade institucional brasileira. Revista da Faculdade de Direito da UFPR, v. 42, p. 103-120, 2005. Disponível em: http://ojs.c3sl.ufpr.br/ojs/index.php/direito/article/view/5178/3894 . Acesso em: 12 mar. 2016.

VIEIRA, José R.; BRASIL, Deilton R. A força normativa dos fatos como ferramenta do ativismo judicial utilizada para alargamento da competência do Supremo Tribunal Federal após a EC 45/04. Verba Juris, v. 6, n.6, p. 301-321, 2007.

WANDERLEY, Claudia Burian. Emancipações municipais em Minas Gerais: estimativas e seus impactos sociais. Rio de Janeiro: FGV, 2007.

Data de submissão: $27 /$ set./ 2018

Data de aceite: $31 /$ jul./2019 